\title{
LACTIC ACID BACTERIA IS BENEFICIAL FOR ORAL APHTHOUS ULCERATIONS - A PRELIMINARY REPORT
}

\begin{abstract}
Hashim BY, Rahman RA, Philip K. Lactic acid bacteria is beneficial for oral aphthous ulcerations - a preliminary report. Annal Dent Univ Malaya 1999; 1: 43 46
\end{abstract}

\begin{abstract}
Recurrent aphthous ulcers of the mouth are difficult to treat because of no known definite aetiology. This paper presents the use of lactic acid bacteria thought to modulate the host immune response to affect improvements in the disease. Twenty-five patients with the disease were treated with 6 lactic bacteria capsules (in the form of OMX capsules) daily for a period of six months, and their responses were evaluated. Seventeen patients $(73.9 \%)$ became free of the disease six months later, while 6 (26.1\%) experienced very dramatic improvements. Two patients were lost to follow-up. It is concluded that lactic acid bacteria is beneficial in the treatment of recurrent aphthous ulcers of the mouth.
\end{abstract}

KEY WORDS : Aphthous ulcers, Lactic acid bacteria.

\section{INTRODUCTION}

Recurrent aphthous ulcerations of the oral cavity (RAS) is a common disease affecting up to about 25 percent of any population. It is usually classified into 3 types, namely the minor, major and herpetiform aphthous ulcerations. The more serious variant of the RAS is the Behcet's Disease (BD) where the ulcers appear not only in the oral cavity but also in the genitalia and the eyes, alongside with other degenerative conditions in the various parts of the body. The aetiology of RAS is not certain, although there are various factors that are thought to play important roles. These include allergy to various chemicals and foods, gluten enteropathy, deficiency of blood iron, Vitamin B and folic acid, sensitivity to adenoviruses, herpes simplex, and Streptococcus Sanguis Type 2A, familial traits, psychological and emotional stress, and immunological disturbances. Recently it has been suggested that RAS or $\mathrm{BD}$ may be caused by human cytomegalovirus(1).

Because of the uncertainty of the aetiology, the outcome of the treatments of RAU and BD are unsatisfactory, and are riddled with unwanted side-effects. The frequent agents used are topical or oral steroids with or without immunosuppressants, topical anaesthetics, antiseptics or antibiotics, supplementary iron, Vitamin B12 and folic acid, cyclosporin A, colchicine, penicillamine, cyclophosphamide, chlorambucil, thalidomide and interferon. However, constant search for better methods of delivering treatments must always be done if the quality of life is to be desired. Looking back into the literature, the authors were awaken to some of the roles that are played by lactic acid bacteria (LAB) in the human body that may be very important in the treatment of RAS. LAB has

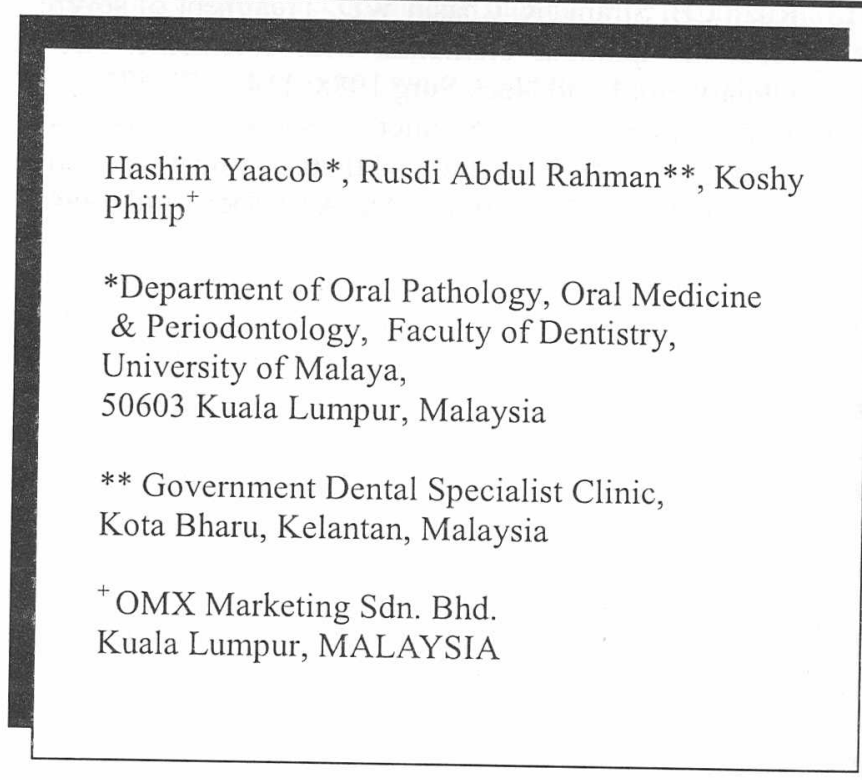

been shown to stimulate the immune defences in animal and human studies and thereby enhancing the non-specific resistance to infections and tumors and also acting as adjuvants of specific immune response $(2,3)$. It stimulates the cells of the human non-specific immune system of myeloid origin to be more active in phagocytosis(3). LAB also stimulates the specific immune system of the human to produce an increased level of serum $\operatorname{IgA}(2,4)$. Various personal communications with dental colleagues have also revealed favourable results when yogurt containing LAB were used to treat RAS. Bifidobacteria, which is one of the LAB, are capable of synthesising some B Vitamins(5).

Basing on the above facts, the authors decided to carry out a clinical trial to determine if the use of LAB was beneficial in the management of RAS.

\section{MATERIALS}

The Ohhira Mountain Fruits Extract Capsules (OMX capsules) containing twelve strains of lactic acid bacteria from the genera Lactobacillus (acidophilus, bulgaricus, casei sp. Casei, fermentum, helveticus sp. Jagurti, plantarum), Bifidobacteria (breve, infantis, longum), Enterococcus (faecium, faecalis) and Streptococcus (thermophilus), 18 amino acids (arginine, lysine, histidine, phenylalanine, tyrosine, leucine, isoleucine, methionine, valine, alanine, glycine, proline, glutamic acid, serine, threonine, aspartic acid, tryptophan, cystine), 9 vitamins (B12, Folic acid, B6, Thiamin, Riboflavin, Niacin, Pantothenic acid, Biotin, Inositol) and 5 minerals (phosphorus, iron, calcium, sodium, potassium) were used as agent for the treatment of RAS. Lactic acid bacteria capsules have been classified as a food supplement referred as probiotic $(6,7)$, which is defined as "live microbial feed supplements which beneficially affect the host animal by improving its intestinal microbial balance"(8). The LAB (OMX) capsule has been officially 
classified by the Agriculture and Agri-Food Canada, Food Production and Inspection Branch as 'food'; by the H.M. Customs and Excise Tariff and Statistical Office for the EUROPEAN COMMUNITY-BINDING TARIFF INFORMATION as 'Health Food'; by the National Food Authority of Australia as "Miscellaneous Food" and as "Food"; by the Pharmaceutical Department of the Ministry of Health of Singapore as a product "not controlled under part I of the Poisons Act and also not subject to product registration so long as no medicinal claims are made".

Twenty-five patients (12 males and 13 females) of the Malay race with RAS ( 5 with the major type, and 20 with the minor type of RAS) between the ages of 13 and 64 years from the state of Kelantan in the north of Malaysia were selected as trial subjects.

\section{METHODS}

Each of the 25 patients with the diagnoses of RAS who has no other relevant medical condition was prescribed $6 \mathrm{LAB}$ (OMX) capsules daily. At the first appointment the number of oral ulcers, their locations and diameters were recorded. No patient had any ulcer at other locations including the genitalia and the eyes. Their age, sex and race were also noted. A venepuncture was performed on each so that the blood profile of differential blood counts, haemoglobin content, serum iron, serum ferritin, serum folate, red cell folate and serum Vitamin B12 which are important factors in RAS could be determined. Each patient was re-examined every two weeks for a period of six months. The patient was also instructed to record daily the number of ulcers present, their sizes, locations and the degree of pain experienced (severe, moderate, slight, no pain). The patient was also asked to record all the four parameters above for any new ulcers that might subsequently developed.

\section{RESULTS}

Out of the 25 patients seen, 2 did not turn up after first appointment and therefore were lost to follow-up. Seventeen patients $(73.9 \%)$ become totally free of RAS by the end of six months after taking 6 tablets of LAB (OMX) capsules daily, while six patients $(26.1 \%)$ did not become totally free of RAS. In these 6 patients however, there was reduction in the number of ulcers present between $66 \%$ to $93 \%$ of the original number; reduction in the size of the ulcers between $50 \%$ to $83 \%$ of the original size; and there was much less pain felt from the ulcers compared to the time before the patient consumed the LAB capsules.

The clinical pictures of typical minor and major RAS in our studies are shown in Figures 1, 2 and 3. The blood levels of haemoglobin, iron, vitamin B12 and folic acid were within normal limits in all the patients except in only three : Patient 1 had a low haemoglobin level of 10.2 (normal 11.5 - $16.5 \mathrm{~g} / \mathrm{dl}$ ); Patient 2 had low folate level of $2.5 \mathrm{ng} / \mathrm{ml}$ (Deficient $<2.8 \mathrm{ng} / \mathrm{ml}$ ); and Patient 20 with low haemoglobin at $12.0 \mathrm{~g} / \mathrm{dl}$ and very low iron at $0.9 \mathrm{omol} / \mathrm{L}$ (normal $5.2-39.9 \mu \mathrm{mol} / \mathrm{L}$ ).

The personal and ulcer data of the twenty-five RAS patients in this study is shown in Table I.

\section{DISCUSSION}

At the end of a six-month treatment with six LAB (OMX) capsules daily, 17 patients $(73.9 \%)$ became totally free of RAS which they previously suffered. It is important to point out that among them, freedom from RAS occurred in 6 patients $(32.3 \%)$ at the end of one month; 10 patients $(58.8 \%)$ at the end of two months; 14 patients $(82.4 \%)$ at the end of four months. Thus it can be accepted that with the same dose of LAB capsules (OMX), the reactions of patients differ markedly from one individual to another. There is always the possibility that the daily intake of the

Figure 1: A minor RAS (Diameter $4 \mathrm{~mm}$ ) on the upper lip of a 37-year-old man.

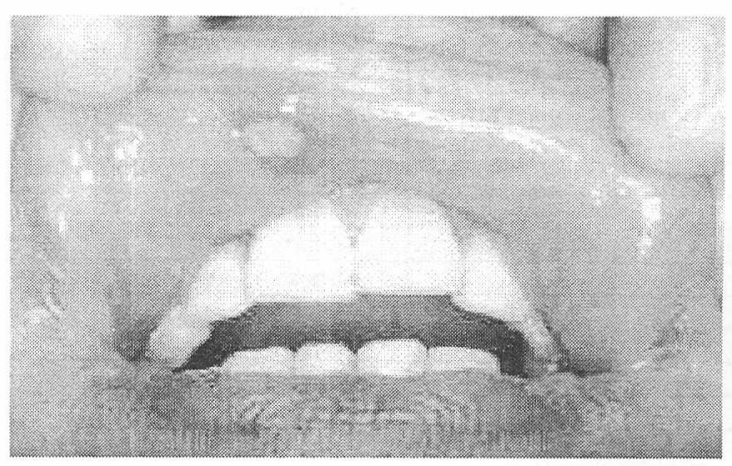

Figure 2 - A major RAS (Diameter 10mm) on the lower lip of a 34-year-old women

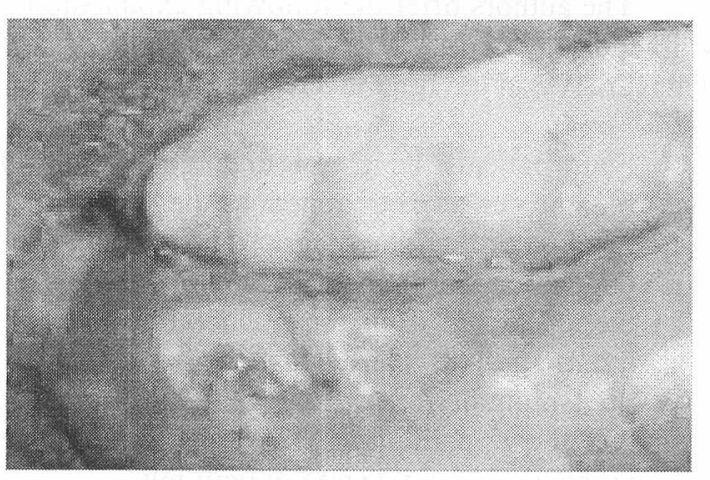

Figure 3: A major RAS (Diameter 10mm) on the tip of the tongue of a 34-year-old man

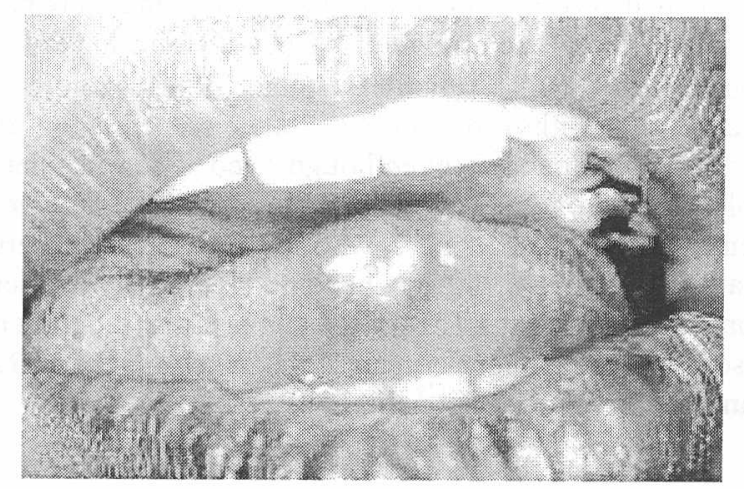


TABLE 1 - The personal and ulcer data of 25 RAS Malay patients treated with 6 lactic acid bacilli capsules daily

\begin{tabular}{|c|c|c|c|c|c|c|c|c|c|c|}
\hline \multirow[t]{2}{*}{ Patient } & \multirow{2}{*}{ Sex } & \multirow{2}{*}{ Age } & \multirow[t]{2}{*}{ Ulcer type } & \multicolumn{2}{|c|}{ Initial ulcer } & \multicolumn{3}{|c|}{ Ulcer decreased to } & \multicolumn{2}{|c|}{ Pain rating } \\
\hline & & & & Number & Diameter $(\mathrm{mm})$ & Number & $\begin{array}{c}\text { Diameter } \\
(\mathrm{mm})\end{array}$ & $\begin{array}{c}\text { After } \\
\text { (days) }\end{array}$ & $\begin{array}{c}\text { Before } \\
\text { treatment }\end{array}$ & $\begin{array}{c}\text { After } \\
\text { treatment }\end{array}$ \\
\hline 1 & $\mathrm{~F}$ & 34 & Major & 2 & 8,14 & 0 & 0 & 60 & Moderate & No pain \\
\hline 2 & $\mathrm{M}$ & 31 & Major & 30 & $3-10$ & 2 & 1 & 180 & Severe & Slight \\
\hline 3 & $\mathrm{M}$ & 34 & Minor & 2 & 1 & 0 & 0 & 90 & Slight & No pain \\
\hline 4 & $\mathrm{~F}$ & 64 & Minor & 2 & 2 & 0 & 0 & 180 & Slight & No pain \\
\hline 5 & $\mathrm{~F}$ & 22 & Minor & 2 & 2 & 0 & 0 & 60 & Slight & No pain \\
\hline 6 & $\mathrm{M}$ & 32 & Minor & 4 & 6 & 0 & 0 & 120 & Moderate & No pain \\
\hline 7 & $\mathrm{M}$ & 45 & Minor & 2 & $5-7$ & 0 & 0 & 180 & Slight & No pain \\
\hline 8 & $\mathrm{~F}$ & 17 & Minor & 1 & 2 & 0 & 0 & 7 & Slight & No pain \\
\hline 9 & $\mathrm{~F}$ & 15 & Minor & 2 & 3,5 & 0 & 0 & 120 & Slight & No pain \\
\hline 10 & $\mathrm{M}$ & 14 & Minor & 1 & 2 & 0 & 0 & 7 & Slight & No pain \\
\hline 11 & $\mathrm{M}$ & 38 & Minor & 3 & 5 & \multicolumn{5}{|c|}{ PATIENT ABSCONDED AFTER FIRST APPOINTMENT } \\
\hline 12 & F & 32 & Minor & 14 & $2-5$ & 1 & 1 & 180 & Severe & Slight \\
\hline 13 & $\mathrm{~F}$ & 48 & Minor & 2 & 1 & 0 & 0 & 7 & Slight & No pain \\
\hline 14 & $\mathrm{M}$ & 37 & Minor & 2 & 3 & 0 & 0 & 90 & Slight & No pain \\
\hline 15 & $\mathrm{~F}$ & 42 & Major & 2 & 10 & 0 & 0 & 180 & Severe & No pain \\
\hline 16 & $\mathrm{~F}$ & 33 & Major & 1 & 10 & 0 & 0 & 30 & Moderate & No pain \\
\hline 17 & $\mathrm{M}$ & 32 & Minor & 3 & $3-8$ & 1 & 3 & 105 & Slight & Slight \\
\hline 18 & $\mathrm{~F}$ & 35 & Minor & 3 & 2 & 0 & 0 & 30 & Slight & No pain \\
\hline 19 & $\mathrm{~F}$ & 16 & Minor & 3 & 2 & 1 & 1 & 120 & Moderate & Slight \\
\hline 20 & $\mathrm{MI}$ & 13 & Minor & 4 & $3-8$ & 0 & 0 & 17 & Slight & No pain \\
\hline 21 & $\mathrm{~F}$ & 27 & Minor & 4 & 2 & 1 & 1 & 75 & Moderate & Slight \\
\hline 22 & $M$ & 37 & Major & 1 & 10 & \multicolumn{5}{|c|}{ PATIENT ABSCONDED AFTER FIRST APPOINTMENT } \\
\hline 23 & $\mathrm{~F}$ & 38 & Major & 2 & 10 & 0 & 0 & 60 & Severe & No pain \\
\hline 24 & $\mathrm{Mi}$ & 45 & Minor & 6 & $2-4$ & 2 & 1 & 60 & Moderate & Slight \\
\hline 25 & $\mathrm{M}$ & 47 & Minor & 5 & $3-5$ & 0 & 0 & 60 & Moderate & No pain \\
\hline
\end{tabular}

prescribed LAB (OMX) capsule regime may not have been adhered to strictly by some patients. Other internal factors that may be inherent in each individual may also play moderating roles.

The authors offer the following explanations as to why freedom from RAS were not achieved in the six patients $(26.1 \%)$ at the time this report was made:-

Four patients have not undergone the full six months period of treatment as they were first seen much later than the others. The patients had only undergone a treatment period of between 2 to 4 months only. Had they undergone the full sixmonth period, there was every possibility that they might be free of RAS, judging from the facts that the remaining RAS were much reduced in number, size and degree of pain felt.

ii.

The dose of 6 lactic acid bacteria capsules daily might not have been the optimum required.

It was interesting to note that eventhough Patient 1 who had low haemoglobin $(10.2 \mathrm{~g} / \mathrm{dl})$, and Patient 20 who had a low haemoglobin $(12.0 \mathrm{~g} / \mathrm{dl})$ and a very low serum iron $(0.9 \mu \mathrm{mol} / \mathrm{L})$, their RAS completely disappeared within 60 and 17 days respectively after starting treatment, eventhough no supplementary replacements of the deficiencies were made available to them. However, Patient 2 who was deficient in serum folate $(2.5 \mathrm{ng} / \mathrm{mL})$, did not become free of RAS after 6 months of treatment. This might suggest that a deficiency in serum folate is more crucial in the development of RAS than the other two components.
In what way does LAB (of the OMX) capsule helped free the patients of their RAS in the present study? It is widely accepted that RAS is an immunological disease. A number of complex immunological reactions take place in the oral tissue that will ultimately break down the covering epithelium of the oral cavity to give rise finally to RAS. As pointed out earlier, LAB has the capacity to modulate the activity of the gut-associated lymphoid tissue (GALT) which play important role in the immune state of the $\operatorname{body}(2,3)$. LAB also stimulates the specific immune system to produce an increased level of serum $\operatorname{Ig} \mathrm{A}$.

The ability of LAB to increase the activity of the phagocytes(3) must be a key factor in combating RAS, as Porter and Scully(9) have stated that in RAS, phagocytosis by polymorphonuclear leukocytes and the chemotaxis to polymorphonuclear leukocytes are defective. Ohhira et al(10) claimed that LAB inhibits MRSA (Methicillin resistant staphylococcus aureus), and also inhibits Helicobacter pylori(11), a bacteria associated with the causation of gastric and duodenal ulcers. One of the suspected causes of RAS is hypersensitivity to Streptococcus sanguis type $2 \mathrm{~A}$. If $\mathrm{LAB}$ were to exert the same inhibitory effect on these bacteria, then LAB would certainly be beneficial in the treatment of RAS. At the moment, there is no known association between these two micro-organisms. Further work on this matter is urgently needed.

\section{CONCLUSION}

Lactic acid bacteria in the form of OMX capsules are beneficial in the treatment of recurrent aphthous ulcers 
of the mouth. Its lack of side effect makes it desirable. As this is the first report of a clinical trial using lactic acid bacteria in the treatment of this disease, it is recommended that more work be carried out in this field.

\section{REFERENCES}

1. Sun A, Chang JG, et al: Human cytomegalovirus as a potential etiologic agent in recurrent aphthous ulcers and Behcet's disease. J. oral pathol Med. 1996, May, 25(5) : 212-8.

2. Link-Amster H, Rochat F, Saudan KY et al : Modulation of a specific humoral immune response and changes in intestinal flora mediated through fermented milk intake. FEMS Immunol Med Micro $1994: 10: 55-64$.

3. Schiffrin EJ, Rochat F, Link-Amster $\mathrm{H}$ et al : Immunomodulation of human blood cells following ingestion of lactic acid bacteria. J Diary Sc:. 1995; 78 : 491-497.

4. Marteau P, Vaerman JP, et al : Effects of intrajejunal perfusion and chronic ingestion of Lactobacillus johnsonii strain LaI on serum concentrations and jejunal secretions of immunoglobulins and serum proteins in healthy humans. Gastroenterol Clin Biol. 1997; $21: 293-298$.

5. Wahlqvist ML : Scientific Dossier - LCI helps reinforce natural balance. Nestle's Diary Products. $1997: 8$.

6. Lilley, DM and Stillwell, RH. : Probiotics : Growth promoting factors produced by microorganisms. Science 1965, $147:$ 747-748.

7. Parker, R.B: Probiotics, the other half of the antibiotic story. 1974: Anim Nutr Health 29 : 4-8.

8. Fuller R.J : A review-probiotics in man and animals. J Appl Bacteriol 1989: $66: 365-378$.

9. Porter SR, Scully C : Orofacial manifestations in primary immunodeficiencies : Polymorphonuclear leukocyres defect. J Oral Pathol Med 1993 : 22, 310311 .

10. Ohhira I, Tamura T, Fui N, Inagaki K, Tanaka H : Antimicrobial activity against MRSA in the culture broth of enterocuccus faecalis $\mathrm{TH} 10$, an isolate from Malaysian fermentation food, Temph. Jap. J Dairy Food Sc 1996 : 45(4), 93-96.

11. Lambert J : unpublished data. 1996, Monash Medical Centre Melbourne, Australia. 